\title{
Terapia Ocupacional na Atenção Básica: a construção de uma prática*
}

\section{Occupational Therapy in Primary Care: the construction of a practice}

\author{
Adriana Miranda Pimentel ${ }^{1}$, Maria Tereza Baraúna da Costa ${ }^{2}$, \\ Fernanda Reis de Souza ${ }^{3}$
}

PIMENTEL, A. M., COSTA, M. T. B., SOUZA, F. R. Terapia Ocupacional na Atenção Básica: a construção de uma prática. Rev. Ter. Ocup. Univ. São Paulo, v. 22, n. 2, p. 110-116, maio/ago. 2011.

RESUMO: Trata-se de experiência de estágio de Terapia Ocupacional na Atenção Básica desenvolvida no Curso de Terapia Ocupacional da Escola Bahiana de Medicina e Saúde Pública em Salvador, na Bahia. O estágio teve início no ano de 2008 em um Centro de Saúde da cidade, fruto de atividades de ensino, pesquisa e extensão do grupo de pesquisa "Modos de Vida e Territórios Urbanos" e constituiu um campo de estudos e práticas voltado para pessoas com deficiência em seus contextos próprios de vida. A partir disto, os estagiários avaliaram e acompanharam pessoas de uma microárea identificadas pela pesquisa, assim como planejaram e realizaram ações do âmbito domiciliar ao territorial. A experiência proporcionou maior integração ensino-serviço, visto que foi respaldada por uma prática condizente com as limitações e possibilidades tanto das pessoas com deficiência quanto do serviço. Proporcionou, também, mudanças na maneira de ver e atuar dos estudantes em dado território.

DESCRITORES: Atenção Primária Básica; Terapia ocupacional; Pessoas com deficiência; Formação de recursos humanos; Pessoas/educação; Capacitação profissional.

\footnotetext{
* Trabalho apresentado no XI Congresso Brasileiro de Terapia Ocupacional, outubro de 2009, Fortaleza, Ceará.

${ }^{1}$. Docente. Instituto de Humanidades, Artes e Ciências Professor Milton Santos. Universidade Federal da Bahia.

2. Docente. Curso de Terapia Ocupacional da Escola Bahiana de Medicina e Saúde Pública - EBMSP, Salvador, Bahia.

3 Terapeuta Ocupacional. Residente do Programa de Residência Multiprofissional em Saúde da Família e Comunidade, Fortaleza, Ceará.

Endereço para correspondência: Adriana Miranda Pimentel. Instituto de Humanidades, Artes e Ciências Professor Milton Santos. Universidade Federal da Bahia. Rua Barão de Jeremoabo, s/n, PAF IV - Campus Universitário de Ondina, Salvador, Bahia CEP: 40170115. e-mail: adriana.pimentel@ufba.br
} 


\section{INTRODUÇÃO}

$\mathrm{E}$

ste artigo baseia-se em experiência de estágio

de Terapia Ocupacional na Atenção Básica

no âmbito do Curso de Terapia Ocupacional

da Escola Bahiana de Medicina e Saúde Pública, na cidade de Salvador, Bahia. Esta experiência teve início no ano de 2008 em um Centro de Saúde modelo tradicional, situado em bairro central da cidade, e nasceu de atividades de ensino, pesquisa e extensão desenvolvidas desde 2003 pelo grupo de pesquisa "Modos de Vida e Territórios Urbanos".

Entre as atividades de ensino, foram oferecidas aulas práticas da disciplina de Saúde Coletiva no Centro de Saúde. Estas aulas permitiram maior aproximação dos alunos com o bairro e a realidade de um Centro de Saúde, o que desencadeou novos projetos: uma pesquisa, iniciada em 2005, para identificar e caracterizar pessoas com deficiência (PCD), suas atividades e formas de participação no bairro; um projeto de extensão, em 2006, que vinculou alunos dos cursos de Fisioterapia e Terapia Ocupacional a ações realizadas com as pessoas identificadas pela pesquisa; e a criação, em 2008, do estágio curricular para alunos do Curso de Terapia Ocupacional, objeto deste artigo.

Esta experiência de ensino é fruto das mudanças que vêm ocorrendo em diversos cursos na área da saúde no Brasil. São mudanças da mais alta relevância, haja vista que a formação de recursos humanos em saúde constitui um dos principais entraves a real implementação do Sistema Único de Saúde - SUS (HADDAD et al., 2010; CECCIM, 2003). A Lei Orgânica da Saúde (BRASIL, 1990) instituiu o SUS como uma escola e, deste modo, os serviços de saúde operam como espaços de prática e ensino. Os cursos devem, portanto, adequar seus currículos aos princípios, diretrizes e propostas do SUS. Esta proposta de mudança curricular iniciou-se em 1990 e tem provocado transformações nos cursos de um modo geral. Surgem, a partir disto, novas demandas e espaços de atuação em contextos específicos onde os cursos se inserem e, consequentemente, novas exigências profissionais de adequação da formação a um modelo de atenção alternativo à lógica curativa e mercantilista para resolver os problemas de saúde.

As reflexões sobre uma atuação do terapeuta ocupacional condizente com as necessidades e demandas dos sujeitos que visa atender e em consonância com os princípios e diretrizes do SUS já ocorrem há algumas décadas, particularmente com a participação de terapeutas ocupacionais no processo de Reforma Sanitária desde a década de 1970. As discussões sobre novos espaços de atuação e novas práticas de intervenção do terapeuta ocupacional, assim como a atuação desse profissional em níveis de atenção de diferentes complexidades no SUS, têm sido possíveis em função do engajamento político da categoria, da exigência de adequação do currículo às Diretrizes Curriculares Nacionais do Ministério da Educação (BRASIL, 2002), da produção científica vinculada aos campos da Saúde Coletiva, Ciências Humanas e Sociais e das experiências que vêm acontecendo em diversos locais do país.

Cada vez mais, pesquisadores, docentes, profissionais e estudantes problematizam e discutem as bases de uma prática que vise à construção de um SUS real e que aponte para uma formação profissional condizente com essas novas demandas e exigências. Em virtude disso, este artigo apresenta uma experiência de estágio curricular de Terapia Ocupacional na Atenção Básica, sua fundamentação, metodologia de ação e resultados preliminares.

\section{AAtenção Básica e os esforços para a integração ensino- serviço}

A ênfase na Atenção Básica é foco de discussões de sanitaristas e pesquisadores em todo o mundo. Essa é uma estratégia na transformação de modelos assistenciais altamente excludentes e curativos em modelos de atenção alternativos que visem à organização do sistema de saúde de forma universal, equitativa, integralizada e com participação social (GIOVANELLA; MENDONÇA, 2008). Caracteriza-se por um conjunto de ações de promoção, prevenção, recuperação e reabilitação a serem realizadas prioritariamente em um território delimitado, o mais próximo possível dos espaços de vida das pessoas (BRASIL, 2007); uma estratégia para a criação/invenção de novas práticas de saúde e para um novo modelo de formação profissional.

Desde a década de 1980, a partir de diferentes experiências e cenários e com vistas a fortalecer perspectivas que ampliem a visão de saúde, surgem propostas de trabalho para além das unidades e equipamentos de saúde, que dialogam com outras formas de organização social e priorizam os sujeitos como agentes vivos desse processo. Como consequência dessas iniciativas, as reflexões acerca da formação profissional em saúde tomam corpo e iniciam processos importantes de mudança, tal como vêm evidenciando os trabalhos divulgados em duas importantes publicações sobre formação e desenvolvimento profissional em saúde (PINHEIRO et al., 2005; BRASIL, 2003).

É notória, na quase totalidade das profissões da saúde, a formação voltada para a clínica centrada na doença e à mercê das instituições as quais, na maioria das vezes, são priorizadas em detrimento dos sujeitos assistidos. Não é 
PIMENTEL, A. M. et al. Terapia Ocupacional na Atenção. Rev. Ter. Ocup. Univ. São Paulo, v. 22, n. 2, p. 110-116, maio/ago. 2011.

por acaso que algumas propostas têm surgido e mobilizado esforços, particularmente a partir da década de 1990, no intuito de produzir conhecimento e construir alternativas que visem a uma maior integração ensino-serviço, a exemplo do Aprender SUS, do Programa Nacional de Reorientação da Formação Profissional em Saúde (Pró-Saúde) e do Programa de Educação pelo Trabalho para a Saúde (PET-Saúde).

Esses aspectos introdutórios permitem compreender o contexto em que se desenvolveu e o processo de criação de um campo de estágio para alunos do Curso de Terapia Ocupacional na Atenção Básica, na Bahia. Trata-se de uma experiência única no estado, nascida dentro de uma instituição privada e tradicional de ensino, situada em Salvador, cujos estágios e práticas ocorrem, predominantemente, em instituições hospitalares e ambulatoriais. O Estado, que já foi palco de muitas lutas e transformações no campo da Saúde Pública, atualmente é um dos mais defasados do Nordeste na implantação das estratégias como o Programa de Agentes Comunitários de Saúde (PACS) e o Programa Saúde da Família (PSF), fundamentais para a consolidação da Atenção Básica (BRASIL, 2009).

O processo de construção do estágio foi marcado por dificuldades tanto relacionadas ao próprio Curso (matriz curricular, formação dos docentes, disponibilidade de discentes e docentes para atividades extramuros), quanto relacionadas ao serviço (que incluem a indisponibilidade dos técnicos para a realização de ações no território e para o atendimento a pessoas com deficiência e o desconhecimento a respeito dos princípios e diretrizes do SUS e da comunidade de abrangência). No processo de integração ensino-serviço, essas limitações e implicações não podem ser evitadas, pois se configuram como práticas herdadas de modelos de educação/formação e de saúde centrados na doença e não em sujeitos. Ao contrário, elas devem ser evidenciadas e acolhidas nos contextos onde se manifestam e confrontadas com outras possibilidades de enfrentamento das situações que se apresentam. A experiência de um estágio pode ser uma via de acesso a novas práticas de saúde, desde que orientada por um modelo de atenção que tenha como foco o sujeito-cidadão. Todavia, para que isto aconteça, é necessário conhecer a realidade que se pretende transformar - sujeitos e seus espaços vividos.

\section{A pesquisa como subsídio para a construção de um estágio}

Para a construção deste campo de prática, considerando as dificuldades descritas acima, foi fundamental a realização de uma pesquisa, tanto para tomar conhecimento da situação de vida e saúde das pessoas com deficiência, quanto para conhecer o bairro onde viviam. Esse processo de investigação foi crucial para sedimentar o estágio.

Com base nas primeiras leituras e discussões sobre os dados da pesquisa e nas experiências de ensino e extensão ocorridas ao longo dos três anos anteriores, deu-se início à construção do estágio curricular. Foi firmado convênio com a Secretaria Municipal de Saúde da cidade de Salvador, estabelecendo-se o Centro de Saúde do bairro de Cosme de Farias como local de referência para o desenvolvimento da proposta.

Cosme de Farias é um bairro central e pobre da cidade de Salvador, com área de 84 hectares e uma população de aproximadamente 40.000 habitantes, segundo dados do último Censo, o que equivale a uma densidade populacional de 422hab./ha (BAHIA, 2005). É um bairro altamente adensado, situado em uma área íngreme da cidade, de cujo cume se enfileiram encostas e baixadas, com ausência de áreas livres, e que conta com apenas uma via de acesso a ônibus e caminhões de lixo. Apesar dos dados do IBGE em relação à infra-estrutura apontarem para condições favoráveis de saneamento básico, há localidades que não possuem coleta de lixo e que não são devidamente assistidas por tratamento de água e esgotamento sanitário.

A distribuição dos moradores, por faixa etária, apresenta predominância de população mais jovem (crianças, adolescentes e jovens), perfazendo um total de quase $50 \%$ da população total. Mais da metade das pessoas responsáveis pelos domicílios possui renda entre $1 / 2$ e dois salários mínimos, o que reforça a percepção de que essa população vive em condições economicamente precárias.

Nesse bairro atuam 61 entidades religiosas, 21 organizações civis e 8 equipamentos governamentais, entre os quais um Centro de Saúde modelo tradicional, que é a unidade de saúde de referência para a população do bairro. Embora não existam equipes do Programa de Saúde da Família, a unidade conta com duas equipes do Programa de Agentes Comunitários de Saúde (PACS), que cobrem aproximadamente $70 \%$ das famílias residentes (PIMENTEL et al., 2007).

$\mathrm{Na}$ pesquisa realizada nas duas áreas de cobertura do PACS, foram identificadas 235 pessoas com deficiência física e sensorial. O perfil do grupo estudado pode ser definido pela predominância de mulheres adultas e idosas, com prevalência de doenças crônico-degenerativas e com deficiência física. Mais da metade não foi alfabetizada ou possui escolaridade incompleta. Observou-se que a rede de apoio social das pessoas identificadas se limita, em grande medida, à família e/ou cuidador, além de vizinhos e igrejas. 
PIMENTEL, A. M. et al. Terapia Ocupacional na Atenção. Rev. Ter. Ocup. Univ. São Paulo, v. 22, n. 2, p. 110-116, maio/ago. 2011.

Práticas como cuidar da casa, assistir televisão e observar o "movimento da rua" estão entre as mais realizadas pelas pessoas com deficiência, caracterizando um estado de isolamento doméstico (PIMENTEL et al., 2007). Seja esta condição estabelecida pela falta de motivação, seja pela presença de barreiras arquitetônicas e geográficas ou psicossociais, tal fato evidencia a urgência na adoção de medidas que favoreçam a participação social.

Estes dados e outras informações resultantes da pesquisa conduziram o planejamento e a metodologia do estágio.

\section{Aspectos metodológicos para orientação da prática}

A perspectiva teórico-metodológica do estágio foi orientada pela experiência desenvolvida por professores da Universidade de São Paulo, especificamente do Laboratório de Reabilitação com Ênfase no Território (ALMEIDA et al., 2000; ALMEIDA; OLIVER, 2001). Esse grupo ancora-se nas estratégias da Reabilitação Baseada na Comunidade e Reabilitação Psicossocial para a reflexão sobre a lógica e a organização da assistência às pessoas com deficiência no Brasil (ALMEIDA, 2000) e tem sido propositivo quanto à formulação de políticas públicas e estratégias de intervenção nos serviços públicos de saúde. O estágio, estruturado com base nesta experiência paulista, visava inicialmente à atenção às pessoas com deficiência identificadas pelo estudo, mas também à mobilização de todo o entorno, incluindo família, vizinhos, rua, bairro e cidade.

Foram estabelecidos os seguintes objetivos de estágio: estimular o estudante à prática de atenção à população com deficiência a partir de uma intervenção territorial, orientada pela perspectiva da clínica ampliada, o que preconiza que a atenção em saúde seja orientada para os sujeitos situados histórico e socialmente em um dado contexto e não centrada na doença como ocorre em uma perspectiva biomédica (CAMPOS, 2001); instrumentalizar o estudante para o uso dos recursos grupais e coletivos, educação em saúde, oficinas e cooperativas, que promovam a atenção a pessoas com deficiência e outros grupos comumente desassistidos pelos serviços de atenção básica; por fim, incentivar a participação dos estudantes em espaços e discussões para a formação de um pensar crítico e reflexivo sobre a atenção à saúde de grupos vulneráveis em um território de abrangência.

O estágio foi estruturado em duas frentes: uma voltada para a intervenção clínica domiciliar, tendo como base a pessoa com deficiência e sua família, partindo das suas necessidades imediatas que, muitas vezes, dizem respeito a uma situação crônica de isolamento em casa ou ao leito, com perdas consideráveis da rede de apoio social; outra voltada para as ações territoriais para viabilizar, criar e ampliar espaços concretos de trocas e possibilidades, com e para além da deficiência, com a participação efetiva dessas pessoas. As atividades foram realizadas, prioritariamente, em diferentes espaços existentes no bairro, tais como entidades religiosas, escolas e associações de moradores.

O Centro de Saúde foi instituição de referência para os estagiários, local de aprendizagem, intervenção e de constante tensionamento, pois buscava-se implementar ações e firmar o compromisso do serviço com as pessoas com deficiência - comumente ausentes nestes equipamentos. Porém, as práticas também extrapolavam o espaço institucional no intuito de ampliar a participação dessas pessoas no bairro e a partir dele.

A experiência relatada ocorreu ao longo do ano de 2008 e contou com a participação de nove alunas do nono período e uma do décimo. Algumas estagiárias participaram do processo desde as aulas práticas da disciplina de Saúde Coletiva em 2003, foram bolsistas de iniciação científica na pesquisa e conheciam o campo de estágio em profundidade, o que contribuiu fortemente para os resultados obtidos.

\section{Alguns resultados para ampliar discussões}

Inicialmente, os estagiários acompanharam pessoas com deficiência em seus domicílios, tendo como referência uma microárea determinada. A determinação de uma microárea se deu com o objetivo de que o estagiário pudesse se apropriar daquele espaço, criar vínculos com o território, conhecer a dinâmica local e desvendar potencialidades. Assim, deviam realizar avaliações da situação de saúde das pessoas e do entorno, pautando-se nos dados de um mapeamento territorial também efetuado pela pesquisa e no próprio convívio com as pessoas e com o lugar, visando elaborar estratégias de ação no bairro e dirigidas às PCD, bem como a outras pessoas e grupos, direta e indiretamente relacionados.

Dentre as situações mais comuns identificadas em âmbito domiciliar, destaca-se a presença de mulheres adultas e idosas residindo sozinhas ou em companhia de um filho e/ou neto, que são considerados seus cuidadores diretos e que se dividem entre as atividades de trabalho fora de casa e os cuidados com o familiar.

O trabalho inicial do estagiário consistiu no contato imediato com a pessoa com deficiência ou um membro da família que, raras vezes, estava presente no domicílio, ou, ainda, com o vizinho que, comumente, conhecia a situação 
PIMENTEL, A. M. et al. Terapia Ocupacional na Atenção. Rev. Ter. Ocup. Univ. São Paulo, v. 22, n. 2, p. 110-116, maio/ago. 2011.

e auxiliava de diferentes formas. As queixas das PCD eram constantes, não a respeito da deficiência propriamente dita, mas das dificuldades financeiras, das faltas (de amigos, de autonomia, de cuidados), dos problemas ligados às condições de vida, que foram paulatinamente acontecendo, com ou sem relação com a deficiência.

A maioria das pessoas acompanhadas pelos estagiários também era cadastrada pelo PACS e recebia mensalmente a visita de um agente comunitário de saúde (ACS). Essa visita previa o acompanhamento da família, especialmente dos indivíduos que estavam sob controle de diabetes e hipertensão. Com freqüência, a solicitação de atendimento a uma pessoa com sequela de acidente vascular cerebral (AVC) acamada há tempos por parte de um agente não era acolhida pelo serviço, haja vista que não existe o Programa Saúde da Família (PSF) no local. Assim, à medida que os estagiários acompanhavam as PCD, elaboravam planos de cuidado condizentes com as necessidades de uma intervenção individual em função do processo de isolamento domiciliar e da vulnerabilidade em que se encontravam essas pessoas. Estas, acamadas por longo tempo, mas muitas vezes com condições clínicas preservadas, passavam a ser o alvo das primeiras intervenções. Desse modo, era possível trabalhar aspectos como a saída do leito para a posição sentada, a alimentação sem ajuda, a higienização com mais independência, as orientações aos cuidadores, entre outras atividades essenciais da vida, por meio da criação de tecnologias assistivas de baixo custo realizadas com materiais existentes na própria comunidade.

Esse primeiro momento da intervenção era fundamental para o próximo passo a ser dado: o resgate da participação social e o fortalecimento da rede de apoio destas pessoas, e não apenas de seus músculos, como acontece em práticas clínicas normatizadoras do corpo. As intervenções visavam a melhorias funcionais necessárias para a conquista de um objetivo maior que era a participação comunitária e a construção de projetos de vida. Para isto, era necessário desenvolver estratégias que envolvessem vizinhos, amigos e familiares, afastados já há algum tempo, e que poderiam colaborar na dinâmica da casa e de cuidados às pessoas com deficiência. Um exemplo disso foi o acionamento de grupos de oração existentes no bairro para que apoiassem as pessoas impossibilitadas de freqüentar a igreja ou templo, mas que desejavam participar desses grupos, na perspectiva de ampliação das redes social e de apoio.

A intervenção no domicílio também estimulou a formação de um grupo intitulado "Oficina de Talentos". Esse grupo surgiu do desejo de uma pessoa acompanhada pelos estagiários e visava à criação de um espaço de troca de experiências artísticas entre pessoas do bairro com e sem deficiências. Assim, em uma ação conjunta entre estagiários e PCD, foi desenvolvida a Oficina. Eles negociaram o espaço, identificaram e mobilizaram as pessoas interessadas, viabilizando sua participação no que se refere ao acesso ao local para a formação do grupo, uma vez que o bairro possui inúmeros obstáculos físicos e geográficos. Foram convidadas pessoas até então acompanhadas apenas no domicílio, entre outras, tais como usuários de um Centro de Atenção Psicossocial (CAPS) e moradores do bairro. $\mathrm{O}$ grupo permitiu conhecer e intercambiar habilidades e potencialidades das pessoas para o campo das artes, mas também ampliou seu escopo, na medida em que proporcionou geração de renda e maior realização pessoal para os participantes.

Essas atividades conquistaram o bairro e seus habitantes e também permitiram atentar para situações até então despercebidas, mas que geravam problemas como a dificuldade de acesso a bens e serviços no bairro e na cidade. Deste modo, iniciou-se um processo de mobilização das PCD para a criação de espaços ainda não existentes no bairro e para o uso de outros restritivos a elas, impulsionado pelas ações territoriais.

É importante destacar que cada estagiário, à medida que trabalhava o vínculo com o lugar, também assumia a responsabilidade pela saúde das PCD da sua microárea, realizando encaminhamentos, sempre que necessário, e garantindo a continuidade das ações em saúde e a longitudinalidade do cuidado. Dessa forma, a atenção à pessoa com deficiência não se encerrava com o ato técnico, mas iniciava-se com ele, buscando minimizar as dificuldades para ampliar horizontes, tanto em nível individual como coletivo, buscando, para isso, articulações setoriais e intersetoriais. As ações territoriais passavam, consequentemente, a compor outra etapa do estágio, porém de forma simultânea e atreladas às ações mais especificamente nucleares.

Neste processo de desenvolvimento das ações coletivas no território identificou-se um aspecto bastante relevante e característico no trabalho com pessoas com deficiência: o desconhecimento sobre direitos e condições de existência das pessoas com deficiência, aspecto também evidenciado na experiência conduzida por Oliver et al. (2004). Foram criados, portanto, Fóruns de Discussão sobre a Deficiência, para que as pessoas com deficiência, familiares, lideranças e gestores pudessem encontrar-se, refletir sobre as dificuldades enfrentadas, propor mudanças e, assim, oferecer visibilidade à problemática vivida pelas PCD. A cada semestre um Fórum foi organizado, com 
PIMENTEL, A. M. et al. Terapia Ocupacional na Atenção. Rev. Ter. Ocup. Univ. São Paulo, v. 22, n. 2, p. 110-116, maio/ago. 2011.

reuniões prévias que aconteciam no bairro, nas quais as PCD, junto com os estagiários, decidiam a temática a ser discutida, a produção do evento, os convidados e até mesmo formas de deslocamento para as PCD dentro do próprio bairro, por causa das dificuldades de acesso.

Algumas situações e discussões ocorridas durante os Fóruns, bem como demandas surgidas em outros eventos, levaram à criação de grupos, à realização de estudos posteriores e oficinas como, por exemplo, a Oficina para Cuidadores de PCD. Também foi criado um grupo para crianças com e sem deficiência, com o objetivo de socializálas através dos recursos lúdicos e das possibilidades existentes no próprio bairro. Dentro desse grupo destinado à brincadeira e à criação de brinquedos, por exemplo, surgiu o desejo pela pizza - "artigo de luxo" e bastante atrativo para as crianças. O grupo, então, organizou um encontro para fazer pizza, que envolveu um padeiro, morador do bairro e vítima de um acidente de trabalho que o impedia de retornar às atividades profissionais, assim como mães e crianças, com e sem deficiência, e que foi realizado em espaço cedido por um templo religioso para essa atividade. Deste grupo nasceu o interesse das mães por espaços de discussão sobre a deficiência e diferentes formas de criação dos filhos. Esta proposta foi incluída no planejamento do estágio para o semestre seguinte.

Estas foram algumas das ações que aconteceram de forma mais sistemática ao longo do estágio. Outras, mais eventuais e circunstanciais, porém, também ocorreram. Houve passeios a parques públicos da cidade, organizados de modo que a deficiência estivesse na pauta, convidando um grupo de dança em cadeira de rodas para um espetáculo aberto a todo o público do parque; participação das PCD do bairro em eventos na cidade relacionados à deficiência, acessibilidade e aos direitos humanos; participação e organização de eventos no bairro, como as Feiras de Saúde dos Terreiros de Candomblé de Cosme de Farias, envolvendo as pessoas com deficiência.

Algumas ações foram fundamentais para que novas demandas e projetos surgissem, dentre os quais um "Diagnóstico sobre a situação das crianças com deficiência". Este projeto foi desenvolvido a partir da percepção dos estudantes sobre a inexpressiva parcela de crianças com deficiência revelada nos dados da pesquisa, o que levantou questionamento sobre as dificuldades na identificação e no diagnóstico precoce de deficiência em crianças, levando à sua aparente invisibilidade durante a prática de estágio.
Assim, os estagiários passaram a buscar ativamente as crianças, através de visitas às escolas do bairro, entidades governamentais e não-governamentais, bem como nas próprias microáreas em que atuavam. Esse levantamento resultou em um relatório inicial que identificou situações novas que poderão contribuir para outros estudos e ações a serem ali desenvolvidos.

\section{CONSIDERAÇÕES FINAIS}

Os aspectos aqui ressaltados representam apenas parte do que ocorreu nos grupos e ações realizados durante o estágio. Inicialmente, julgou-se importante evidenciar o ponto de partida para a criação de um campo de estágio no Curso de Terapia Ocupacional. É necessário frisar que o que foi construído é fruto de outras experiências e estudos que já têm uma história. O lugar onde ocorreu a experiência foi definido a partir de um reconhecimento prévio do contexto, entendido aqui como o local onde as pessoas vivem e realizam coisas. O estágio não surgiu de demandas externas ou de mercado; foi, ao contrário, pautado em situações concretas que definiram os caminhos a serem seguidos.

Os dados oficiais obtidos do IBGE mostram um perfil da população do bairro diferente daquele evidenciado pela pesquisa e prática cotidiana com as pessoas com deficiência. A prática fez emergir outras demandas e necessidades não evidenciadas pela pesquisa, mas que se relacionavam com o desejo das pessoas do lugar. Revelou, também, a situação de determinados grupos que não estão em evidência nas ações programáticas e, muitas vezes, "invisíveis" para os técnicos de saúde, como, por exemplo, os cuidadores de pessoas com deficiência ou pessoas com alguma enfermidade que necessitam de cuidados intensivos.

A deficiência implica ausência ou limitação de determinada estrutura ou função do corpo, mas a pobreza, a falta de informação e de acesso aos meios exacerba as dificuldades decorrentes destas perdas e/ou restrições. A precariedade nas condições de vida existentes coloca as pessoas com deficiência em uma situação ainda pior do que a vivida pela população geral do bairro. Este panorama justifica práticas de atenção construídas com e para as pessoas com deficiência, práticas estas que permitirão alcançar uma formação profissional mais integrada, realista, propositiva e coerente com a realidade da maioria das pessoas, usuários do Sistema Único de Saúde.

Colaboradores: As autoras trabalharam juntas em todas as etapas de elaboração do manuscrito. 
PIMENTEL, A. M. et al. Terapia Ocupacional na Atenção. Rev. Ter. Ocup. Univ. São Paulo, v. 22, n. 2, p. 110-116, maio/ago. 2011.

PIMENTEL, A. M., COSTA, M. T. B., SOUZA, F. R. Occupational Therapy in Primary Care: the construction of a practice. Rev. Ter. Ocup. Univ. São Paulo, v. 22, n. 2, p. 110-116, maio/ago. 2011.

ABSTRACT: This article presents a practice placement experience in Primary Care within the Occupational Therapy degree course at Escola Bahiana de Medicina e Saúde Pública, located in Salvador, Brazil. The practice in a healthcare center, which began in 2008, was the result of teaching, research and extension activities developed by the research group "Livelihoods and Urban Territories" and constituted a field of study and practice regarding people with disabilities in their own environment. The trainees evaluated and followed the people of a micro-area identified by the research, as well as planned actions to be carried out at home and within the community. The experience provided better teaching-service integration as it was supported by a practice which took into account the limits and possibilities of both the people with disabilities and the healthcare center. Furthermore, it changed the way students perceived and acted in a given territory.

KEY WORDS: Primary health care; Occupational therapy; Disabled persons; Human resources formation; Persons/education; Professional training.

\section{REFERÊNCIAS}

ALMEIDA, M. C. Saúde e reabilitação de pessoas com deficiência: politicas e modelos assistenciais. Tese (Doutorado) - Faculdade de Ciências Médicas, Universidade de Campinas, Campinas, 2000.

ALMEIDA, M. C.; TISSI, M. C.; OLIVER, F. C. Deficiência e Atenção Primária em Saúde: do conhecimento à invenção. Revista de Terapia Ocupacional da Universidade de São Paulo, v. 11, n.1, p. 35-44, 2000.

ALMEIDA, M. C.; OLIVER, F. C. Abordagens comunitárias e territoriais em reabilitação de pessoas com deficiências: fundamentos para a terapia ocupacional. In: DE CARLO, M. M. R. P.; BARTALOTTI, C. C. (Orgs.). Terapia ocupacional no Brasil: fundamentos e perspectivas. São Paulo: Plexus, 2001.

BAHIA. Companhia de Desenvolvimento Urbano da Bahia CONDER. Dados sociodemográficos do bairro de Cosme de Farias. Salvador: IBGE/SIG, 2005.

BRASIL. Lei Orgânica da Saúde. Lei 8.080/90, de 19 de setembro de 1990.

BRASIL. Conselho Nacional de Educação. Resolução CNE/CES 6, de 19 de fevereiro de 2002. Diretrizes Curriculares Nacionais do Curso de Graduação em Terapia Ocupacional. Diário Oficial da União, Brasília, DF, 4 mar. 2002. Seção 1, p. 12.

BRASIL. Ministério da Saúde. Observatório de recursos humanos em saúde no Brasil: estudos e análises. Organizado por André Falcão et al. Rio de Janeiro: FIOCRUZ, 2003.

BRASIL. Ministério da Saúde. Secretaria de Atenção Básica. Departamento de Atenção Básica. Política nacional de atenção básica. 4a. ed. Brasília, DF, 2007.

BRASIL. Ministério da Saúde. Agência Saúde. Ministro convoca prefeitos a ampliar cobertura em saúde-BA. 9 fev. 2009.

Recebido pra publicção: 22/06/2011

Aceito para publicação: 22/07/2011
Disponível em: <http://sus20anos.saude.gov.br/portal>. Acesso em: 30 ago. 2009.

CAMPOS, R. O. Clínica: a palavra negada - sobre as práticas clínicas nos serviços substituídos de saúde mental. Saúde em Debate, v. 25, n. 58, p.98-111, 2001.

CECCIM, R. B. Formação e desenvolvimento na área da saúde. In: BRASIL. Ministério da Saúde. Organizado por André Falcão et al. Observatório de recursos humanos em saúde no Brasil: estudos e análises. Rio de Janeiro: Fiocruz, 2003.

GIOVANELLA, L.; MENDONÇA, M. H. M. Atenção Primária à Saúde. In: GIOVANELLA, L. et al. (Orgs.). Políticas e sistema de saúde no Brasil. Rio de Janeiro: Fiocruz, 2008.

HADDAD, A. E.; MORITA, M. C.; PIERANTONI, C. R.; BRENELLI, S. L.; PASSARELLI, T.; CAMPOS, F. E. Formação de profissionais de saúde no Brasil: uma análise no período de 1991 a 2008. Revista de Saude Publica, v. 44, n. 3, p. 383-393, 2010.

OLIVER, F. C.; TISSI, M. C.; AOKI, M.; VARGEM, E. F.; FERREIRA, T. G. Participação e exercício de direitos de pessoas com deficiência: análise de um grupo de convivência em uma experiência comunitária. Interface - Comunicação e Saúde, Educacional, v. 8, n. 15, p. 275-88, 2004.

PIMENTEL, A. M., COSTA, M. T. B.; SOUZA, F. R. Conociendo a las personas con deficiencia en un barrio de Salvador, Bahia, Brasil. In: VII CONGRESSO ARGENTINO E VII CONGRESSO LATINOAMERICANO DE TERAPIA OCUPACIONAL, 2007, Mar del Plata Anais. Argentina, 2007.

PINHEIRO, R.; CECCIM, R. B.; MATTOS, R. A. (Orgs.). Ensinar saúde: a integralidade e o SUS nos cursos de graduação na área da saúde. Rio de Janeiro: IMS/UERJ:CEPESQ: ABRASCO, 2005. 